\title{
Effect of Salt and Water Stress on Fruit Quality, Physiological Responses, Macro- and Micro-Element Contents in Leaves of Satsuma Mandarin Trees under Greenhouse Conditions
}

\author{
Kunihisa MORINAGA ${ }^{1 *}$ and Steve R. SYKES ${ }^{2}$ \\ ${ }^{1}$ Department of Slope Land Utilization, Shikoku National Agricultural Experiment Station \\ (Zentsuji, Kagawa, 765-0053 Japan) \\ ${ }^{2}$ CSIRO, Plant Industry (PMB, PO Merbein, Vic., 3505 Australia)
}

\begin{abstract}
Experiments were conducted using Satsuma mandarin trees grown in small containers to investigate the effects of mild salt ( 5 and $10 \mathrm{mM} \mathrm{NaCl}$ in irrigation water) and water stress on growth, photosynthesis, transpiration, fruit quality as well as macro- and micro-element contents in leaves of Silverhill Satsuma mandarin (Citrus unshiu Marc.) grafted on trifoliate orange (Poncirus trifoliata (L) Raf.) rootstocks. Salt and, to a greater extent, water stress treatments resulted in reduced photosynthetic rates, although there were no significant effects on tree growth estimated by recording the increase in stem diameter. Water stress decreased the leaf water potential and increased the stomatal resistance compared to control and salt-stressed trees which showed similar values, while the concentrations of sodium and chloride of the spring-flush leaves were not affected by the salt or water stress treatments. Potassium concentration of these leaves, however, was reduced significantly by $10 \mathrm{mM} \mathrm{NaCl}$ and water stress. Fruit maturity was advanced by water stress although the fruit size (diameter) and fresh weight were reduced. Internal fruit quality in terms of Brix value and Brix:citric acid ratio was improved for the trees irrigated with $10 \mathrm{mM} \mathrm{NaCl}$ solutions or subjected to water stress.
\end{abstract}

Discipline: Horticulture

Additional key words: photosynthesis, water potential, stomatal conductance, sugar, acid

\section{Introduction}

Satsuma mandarin (Citrus unshiu Marc.) is one of the major citrus varieties grown in the world. It is also important in several other countries, mainly Spain and to a lesser extent Korea, Mediterranean countries and China $^{14)}$. In addition to traditional field cultivation, emphasis has been placed on developing other cultivation practices in Japan to extend the season for Satsuma mandarin production. These methods have included cultivation in plastic greenhouses ${ }^{11)}$ and the use of restricted root culture systems, either in open ground or in containers ${ }^{19)}$. These alternative methods of cultivation aim to produce fruits of the highest quality off-season, for high financial returns to growers to offset high production costs. Fruit quality is of paramount importance in these systems of cultivation. Control of moisture availability in soil and fertilization are very important to produce high quality fruits. Irrigation must be cut off during plastic greenhouse cultivation of Satsuma mandarins, as fruits ripen, to increase the sugar level, even though the fruit size may be reduced as a result ${ }^{11)}$.

Water stress has been reported to increase the fruit

This paper contains a part of the results of the studies carried out under the fellowship program for rootstock improvement implemented in Australia and sponsored by CSIRO, Division of Plant Industry (formerly Division of Horticulture) from September 1991 to August 1992.

Present address:

${ }^{1}$ Persimmon and Grape Research Center, National Institute of Fruit Tree Science (Akitsu, Hiroshima, 729-2494 Japan).

*Corresponding author: fax +81-846-45-5370, e-mail forest@akt.affrc.go.jp

Received 1 December 1999, accepted 24 April 2000. 
sugar content of Satsuma mandarins ${ }^{16)}$. Levy et al. ${ }^{4)}$ have reported that fruit juice sugar levels and sugar:acid ratios in grapefruits increased as a result of water stress caused by irrigation applied at long intervals and that salt stress induced similar results. Fruit physical characteristics such as weight, size, peel thickness and juice percentage were only affected by water and not by salt stress in grapefruit. In other reported investigations, salinity reduced fruit weight and increased juice TSS (total soluble solids) in lemons ${ }^{12}$, but had no effect on Valencia orange fruit quality except for a decrease in rind thickness. Salinity also delayed fruit maturation in Valencia oranges ${ }^{2)}$. The effects of salinity on citrus fruit quality appear to vary with the citrus varieties and between investigations ${ }^{6}$.

In Australia, Silverhill Satsuma mandarin is one of the major mandarin cultivars. Irrigation water applied in citrus orchards including those with Silverhill contains a certain amount of salt depending on the water sources. In addition, most citrus trees might have been subjected to water stress conditions, especially in the summer season. Therefore, the effect of both water and salt stress on Silverhill Satsuma mandarin should be investigated because few data are available. Thus we investigated the effect of mild salt stress on fruit quality and physiological characteristics such as $\mathrm{CO}_{2}$ gas exchange and transpiration in Satsuma mandarin trees compared to the effect of water stress in a greenhouse experiment because the effect of salt stress on Satsuma mandarin fruit quality had not been evaluated in Australia in spite of the commercial importance of the fruits. As Satsuma mandarin is generally grafted on trifoliate orange rootstock, which is saltsensitive due to its low salt exclusion ability compared to other rootstocks ${ }^{17)}$, a low level of salt stress was applied.

\section{Materials and methods}

Thirty, 2-year-old Silverhill Satsuma mandarin trees grafted on trifoliate orange (Poncirus trifoliata (L.) Raf.) rootstocks were used in this study. The trees were selected for uniformity, transplanted from their nursery containers into $10.8 \mathrm{~L}$ pots containing sterile potting media consisting of sand, peat and perlite $(5: 3: 2)$ and placed on a bench in an air-conditioned greenhouse in which the heating was programmed at $25^{\circ} \mathrm{C}$ and cooling at $30^{\circ} \mathrm{C}$. The trees were irrigated daily with a quarter strength No.1 nutrient solution containing water ${ }^{3)}$. Iron in the solution was supplied as ethylenediaminetetra-acetic acid ferric monosodium salt $\left(1.25 \times 10^{-5} \mathrm{M} \mathrm{Fe}\right)$. Twenty of the 30 trees flowered during the first week of October 1991. Fruitlets were allowed to develop until November 6 when they were thinned to 3 per plant, although, due to natural abscission, some plants only retained one or two fruitlets. These 20 fruiting trees were randomly assigned to one of 4 treatments such that there were 5 replications per tree per treatment on October 10. The treatments were as follows: trees irrigated twice daily with a quarter strength No.1 nutrient solution (control), trees irrigated twice daily with a quarter strength No.1 nutrient solution containing $5 \mathrm{mM}$ (low salt treatment) or $10 \mathrm{mM} \mathrm{NaCl}$ (high salt treatment), and water-stressed trees (water stress treatment) which were irrigated once every 10 days with No.1 nutrient solution in November, January, March and April and irrigated once every 2 days in December and February to avoid severe and prolonged water stress.

Before the onset of the experiments and throughout the experimental period, the following measurements were performed: photosynthetic $\mathrm{CO}_{2}$ gas exchange was determined using a LI-COR LI6200 portable photosynthesis unit at a photosynthetic photon flux density of $1,000-1,500 \mu \mathrm{mol} \mathrm{m} \mathrm{m}^{-2} \mathrm{~s}^{-1}$, temperature of $25-28^{\circ} \mathrm{C}$ and relative humidity of $75-85 \%$. On each date, the measurements were performed on the same attached 5 leaves per tree that were tagged between 10:00 and 12:00 h. Stomatal resistance of the same attached 5 leaves per tree was measured using an automatic porometer (Delta-T Device Mk. 3) between 11:00 and 13:00 h on each date. Predawn water potential (maximum leaf water potential in a day) was measured for 3 detached leaves per tree before sunrise using a pressure chamber (PMS Instrument Company). Chlorophyll content was determined for 5 flush leaves per tree using a Minolta Spad 501 meter. Tree growth was estimated by recording the increase in stem diameter.

Thirty-two weeks after flowering, the trees were harvested destructively and separated into roots, old leaves, old stem, spring-flush stem, leaves and fruits. External color of fruits was assessed based on a color chart and recorded as the ratio between orange and green rind. Fruits were weighed and their diameter was measured before peeling. Juice was extracted and the Brix value and percentage of citric acid were determined using a portable refractometer and automatic acid titrator, respectively. All the tissues were dried at $60^{\circ} \mathrm{C}$ and weighed. Spring-flush leaves were ashed at $540^{\circ} \mathrm{C}$, extracted with nitric acid and analyzed using the methods described by Walker ${ }^{18)}$, that is, the contents of sodium, potassium and calcium were analyzed by the spectroflame method, and content of chloride was analyzed using a Buchler Chloridemeter. The contents of these elements were expressed on a percentage dry weight basis. 


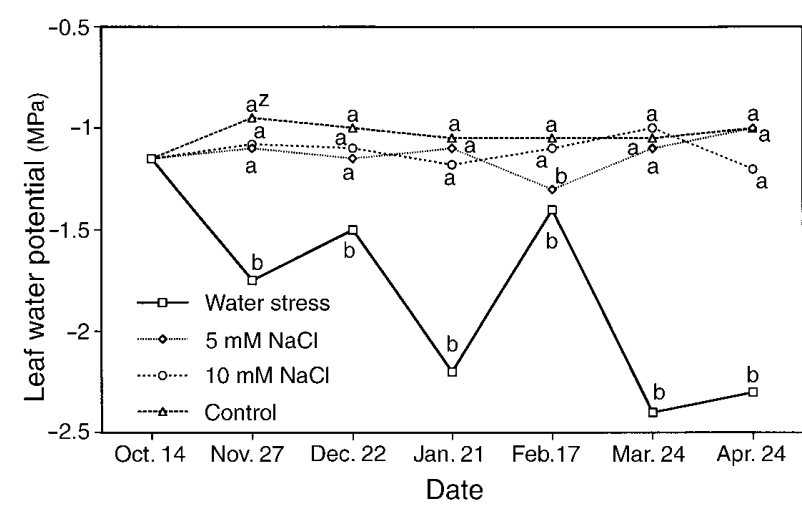

Fig. 1. Changes in leaf water potential of Silverhill Satsuma mandarin under greenhouse conditions and different irrigation regimes

$z$ : Duncan's multiple range test $(\mathrm{p}=0.05)$.

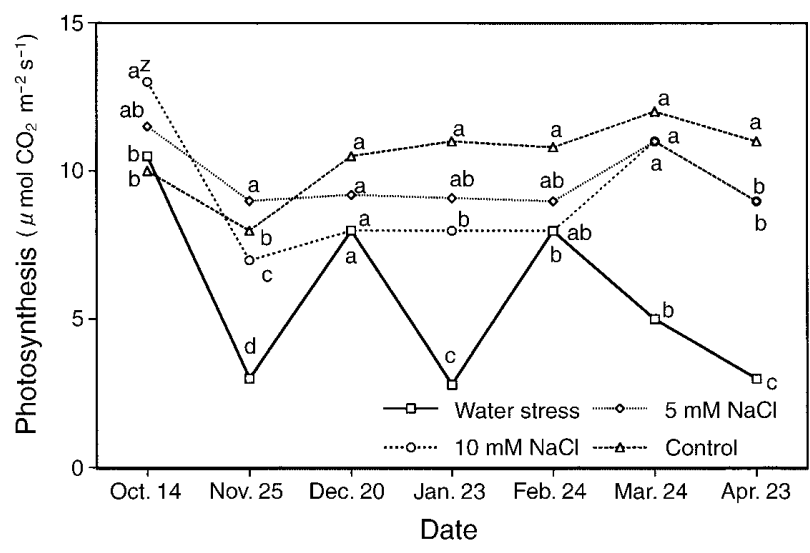

Fig. 2. Changes in photosynthetic rate of Silverhill Satsuma mandarin under greenhouse conditions and different irrigation regimes

z: Duncan's multiple range test $(\mathrm{p}=0.05)$.

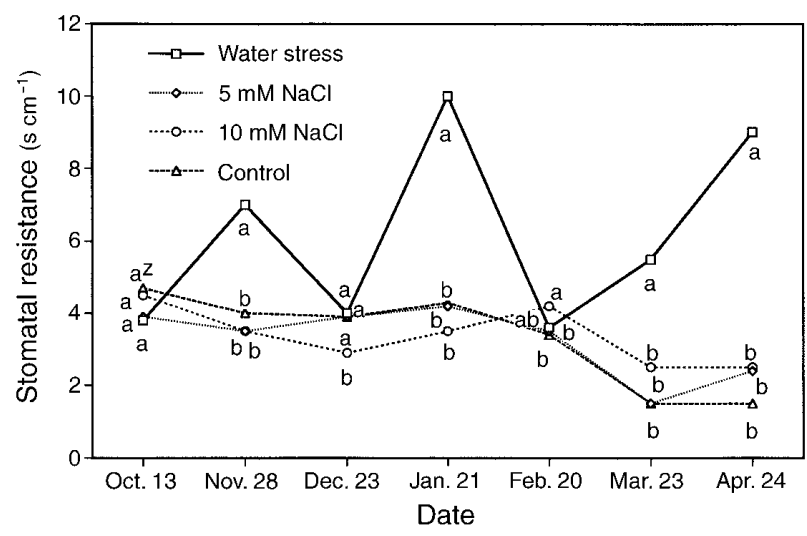

Fig. 3. Changes in stomatal resistance of Silverhill Satsuma mandarin under greenhouse conditions and different irrigation regimes

$\mathrm{z}$ : Duncan's multiple range test $(\mathrm{p}=0.05)$.

\section{Results}

Leaf water potential of the water-stressed trees decreased significantly during the experiments compared to the salt-treated and control trees which showed similar values (Fig. 1). Photosynthetic rates of leaves of the water-stressed trees depended on the maximum leaf water potential (Fig. 2). By the end of the experiments, however, the values were significantly lower than those of the trees in the other treatments. The photosynthetic rates of leaves of the salt-treated trees were lower after a period of 40-60 days of salt treatment compared to the control trees and on some sampling dates these differences were significant. Except on November 25 (35 days after the onset of the salt treatments), there were no differences in the photosynthetic rates of leaves between the trees irrigated with either 5 or $10 \mathrm{mM} \mathrm{NaCl}$ (Fig. 2).

In the same way, the stomatal resistance of the water-stressed trees increased significantly except in December and February compared to the salt-treated and control trees which showed similar values (Fig. 3). The various treatments did not affect the leaf chlorophyll content.

While there were no significant effects of the treatments on stem growth, the increase rate of the mean stem diameter for the control trees was greater than that for the salt-treated and water-stressed trees. Mean stem diameter increased 1.39-, 1.38-, 1.26-, and 1.24-fold during the experimental period for the control, $5 \mathrm{mM} \mathrm{NaCl}, 10 \mathrm{mM}$ $\mathrm{NaCl}$ and water stress treatments, respectively.

Although marginally higher, the chloride concentration of the salt-treated spring-flush leaves was not significantly higher than that of control trees (Table 1). Similarly, the treatments applied had no significant effects on the leaf sodium or calcium concentration. Potassium concentration, however, was significantly different between the treatments (Table 1).

Treatments exerted significant effects on the rind color development and fruits from the water-stressed plants were more advanced in this characteristic. Salt and water stress treatments decreased the fruit diameter and weight. Fruit diameter was reduced significantly by $10 \mathrm{mM} \mathrm{NaCl}$ and water stress, whereas fruit weight was only reduced significantly for the trees irrigated with 10 $\mathrm{mM} \mathrm{NaCl}$ (Table 2).

Peel weight decreased significantly compared to that of the controls in the water-stressed and trees irrigated with $10 \mathrm{mM} \mathrm{NaCl}$. Percentage of peel on a fresh weight basis decreased in all the treatments compared to the controls (Table 2).

Water-stressed trees produced fruits with the highest juice Brix value, which was significantly higher than 
Table 1. Effect of $\mathrm{NaCl}$ and water stress on concentrations of sodium, potassium, calcium and chloride in spring-flush leaves of Silverhill Satsuma mandarin grafted on trifoliate orange rootstock grown under greenhouse conditions

\begin{tabular}{lcccc}
\hline \hline \multirow{2}{*}{ Treatments } & \multicolumn{4}{c}{ Macro- and micro-element contents in leaves } \\
\cline { 2 - 5 } & Sodium & Potassium & Calcium & Chloride \\
\hline Water stress & $0.055 \mathrm{a}$ & $0.864 \mathrm{a}^{\mathrm{z}}$ & $3.660 \mathrm{a}$ & $0.043 \mathrm{a}$ \\
$10 \mathrm{mM} \mathrm{NaCl}$ & $0.060 \mathrm{a}$ & $0.723 \mathrm{ab}$ & $3.696 \mathrm{a}$ & $0.069 \mathrm{a}$ \\
$5 \mathrm{mM} \mathrm{NaCl}$ & $0.078 \mathrm{a}$ & $1.105 \mathrm{bc}$ & $3.758 \mathrm{a}$ & $0.086 \mathrm{a}$ \\
Control & $0.075 \mathrm{a}$ & $1.239 \mathrm{c}$ & $3.721 \mathrm{a}$ & $0.044 \mathrm{a}$ \\
\hline
\end{tabular}

Data are means $(\mathrm{n}=10)$

Macro- and micro-element contents expressed as mg/100 mg DW.

$\mathrm{z}$ ): Mean separation within columns by Duncan's multiple range test at $\mathrm{p}<0.05$.

that of the fruits from control trees. Trees irrigated with $10 \mathrm{mM} \mathrm{NaCl}$ also produced fruits with a significantly higher juice Brix value than that of the fruits from control trees. There were no significant effects of the treatments on juice citric acid levels although the mean for fruits from water-stressed trees was higher than that for other treatments. There were significant effects of the treatments on the Brix:acid ratio in the juice of the fruits from trees irrigated with $10 \mathrm{mM} \mathrm{NaCl}$ which showed the highest mean ratio while control trees showed the lowest value (Table 2).

\section{Discussion}

In the current experiments, fruits from trees subjected to water stress showed the highest juice Brix value (above 8 ) and the trees irrigated with $10 \mathrm{mM} \mathrm{NaCl}$ produced fruits with the highest mean Brix:acid ratio of 9.6. As reported for grapefruits ${ }^{4)}$, it is interesting to note that water stress resulted in a higher juice Brix value for Sil- verhill Satsuma mandarin. Also, it was noteworthy that the fruits from water-stressed trees were further advanced in terms of rind color development. Control of irrigation in greenhouse cultivation of citrus trees in Japan is important for the production of fruits of highest quality as in the case of grapefruit ${ }^{4)}$ and lemon ${ }^{12)}$. Salinity (10 mM $\mathrm{NaCl}$ ) increased the juice Brix levels in Silverhill Satsuma mandarins in these experiments. There was a difference between the data reported in grapefruit by Levy et al. ${ }^{4}$, in that the mean fruit weight of Silverhill was reduced by the $10 \mathrm{mM} \mathrm{NaCl}$ treatment. This outcome is similar to the data reported by Nieves et al. ${ }^{12)}$. The effects of salinity on citrus fruit quality vary depending on the cultivars and varieties ${ }^{6}$. Even though the fruit weight was reduced from $141.9 \mathrm{~g}$ for the control trees to $116.3 \mathrm{~g}$ for the trees irrigated with $10 \mathrm{mM} \mathrm{NaCl}$, it would still be quite acceptable based on market standards.

Water stress and salinity applied to the Silverhill Satsuma mandarin trees in these experiments improved the quality of the fruits and could result in an earlier har-

Table 2. Effect of $\mathrm{NaCl}$ and water stress on the fruit characteristics of Silverhill Satsuma mandarin harvested from container-grown trees under greenhouse conditions

\begin{tabular}{lcccccccc}
\hline \hline & \multicolumn{7}{c}{ Fruit characteristics } \\
\cline { 2 - 8 } Treatments & $\begin{array}{c}\text { Peel } \\
\text { color }^{\mathrm{a})}\end{array}$ & $\begin{array}{c}\text { Fruit } \\
\text { diameter } \\
(\mathrm{mm})\end{array}$ & $\begin{array}{c}\text { Fruit } \\
\text { weight } \\
(\mathrm{g})\end{array}$ & $\begin{array}{c}\text { Peel } \\
\text { weight } \\
(\mathrm{g})\end{array}$ & $\begin{array}{c}\text { Peel } \\
\text { ratio } \\
(\%)\end{array}$ & $\begin{array}{c}\text { Juice } \\
\text { Brix } \\
\text { value }\end{array}$ & $\begin{array}{c}\text { Juice } \\
\text { citric } \\
\text { acid }(\%)\end{array}$ & $\begin{array}{c}\text { Brix:acid } \\
\text { ratio }\end{array}$ \\
\hline Water-stress & $3.7 \mathrm{~b}^{\mathrm{z})}$ & $64.8 \mathrm{bc}$ & $122.5 \mathrm{ab}$ & $30.8 \mathrm{bc}$ & $25.2 \mathrm{~b}$ & $8.1 \mathrm{c}$ & $0.89 \mathrm{a}$ & $9.2 \mathrm{ab}$ \\
$10 \mathrm{mM} \mathrm{NaCl}$ & $1.5 \mathrm{a}$ & $63.3 \mathrm{c}$ & $116.3 \mathrm{~b}$ & $26.8 \mathrm{c}$ & $23.0 \mathrm{c}$ & $7.6 \mathrm{~b}$ & $0.79 \mathrm{a}$ & $9.6 \mathrm{~b}$ \\
$5 \mathrm{mM} \mathrm{NaCl}$ & $0.6 \mathrm{a}$ & $67.6 \mathrm{ab}$ & $133.7 \mathrm{ab}$ & $34.4 \mathrm{ab}$ & $25.5 \mathrm{~b}$ & $6.9 \mathrm{a}$ & $0.79 \mathrm{a}$ & $8.8 \mathrm{a}$ \\
Control & $1.1 \mathrm{a}$ & $69.0 \mathrm{a}$ & $141.9 \mathrm{a}$ & $39.6 \mathrm{a}$ & $27.8 \mathrm{a}$ & $6.8 \mathrm{a}$ & $0.79 \mathrm{a}$ & $8.5 \mathrm{a}$ \\
\hline
\end{tabular}

Data are means.

a): Rind color assessment of the ratio of orange to green rind.

b): \% peel calculated on a fresh weight basis.

$\mathrm{z})$ : Mean separation within columns by Duncan's multiple range test at $\mathrm{p}<0.05$. 
vest. This investigation, however, can only be considered to be preliminary, as it did not allow for a thorough assessment of the use of such stresses in terms of tree productivity. The trees were not allowed to retain all the fruits that were set after flowering and reduction in fruit yield may be expected. Maas ${ }^{6)}$ reviewed this aspect, stating that the reduction in fruit yield caused by salt stress was due primarily to a decrease in the number of fruits per tree rather than to a decrease in weight per fruit. Most of the data relating to yield reduction originated from studies on sweet oranges ${ }^{6)}$. In the current experiments, the stresses imposed resulted in a cost to the trees in terms of a reduction in the photosynthetic rates.

The photosynthetic rate of leaves and leaf water potential of the water-stressed trees were reduced compared to those of the control and salt-stressed trees. Moreover, the stomatal resistance of the water-stressed trees increased significantly. The decreases in the photosynthetic rate of the water-stressed trees may have been due to a reduction in the leaf water content. Photosynthesis of Satsuma mandarin leaves has been found to decrease when the leaf water potential decreased below a value of $-1.5 \mathrm{MPa}^{9)}$. Similarly, in the experiments described here, the photosynthetic rate declined when the leaf water status fell below $-1.5 \mathrm{MPa}$. The data of the stomatal reaction shown in Fig. 3 indicate that water stress causes a photosynthetic reduction due to stomatal closure. Furthermore, photosynthesis reduction induced the suppression of fruit growth. Severe and/or prolonged water stress can lead to an increase in the fruit juice sugar content, but is likely to suppress fruit growth partly because of the reduction of photoassimilates due to photosynthesis reduction. Water stress also causes a reduction of micro-element absorption like potassium which affects stomatal opening and closing.

Sugar accumulation in higher plants under water stress conditions has been investigated in terms of osmotic regulation in the cells ${ }^{7,8)}$. Water-stressed Satsuma mandarin fruits showed the highest sugar content in these experiments, presumably due to osmoregulation during the exposure to water stress in contrast to photosynthesis suppression. Moderate water stress control is required to produce fruits with a high juice sugar content and optimum size ${ }^{9,10)}$.

In previous studies it was reported that salinity reduced the rates of net $\mathrm{CO}_{2}$ assimilation for orange leaves $^{5)}$ and for deciduous tree species ${ }^{20)}$. Lloyd et $\mathrm{al}^{5 \text { ) }}$. discussed the mechanism of the reduction of $\mathrm{CO}_{2}$ assimilation. The photosynthetic rates in the $5 \mathrm{mM}$ and $10 \mathrm{mM}$ $\mathrm{NaCl}$ salt-stressed trees decreased compared to those of the controls during the experiments, especially for trees irrigated with $10 \mathrm{mM} \mathrm{NaCl}$. However, this reduction was not severe. Therefore, salt-stressed trees showed a lower potassium concentration than the control trees, although no significant differences in the sodium and calcium contents were detected among the treatments. Leaf potassium concentration was reduced due to salts, particularly $10 \mathrm{mM} \mathrm{NaCl}$, and in the water-stressed trees. Leaf potassium concentration affects the photosynthesis through inhibition of the Hill reaction ${ }^{15)}$ and $\mathrm{CO}_{2}$ diffusion and assimilation in the mesophyll ${ }^{13)}$. This may explain why the photosynthetic rates were reduced in the salt- and water-stressed Silverhill Satsuma mandarin trees.

Salt-stressed trees showed an increase in the juice sugar content, presumably due to the decrease of water use efficiency through osmoregulation and reduction of the soil water potential ${ }^{1)}$. However, no significant differences in the leaf water potential and stomatal resistance were observed in the current experiments (Figs. 1 and 3) for unknown reasons. Further investigations should be carried out to clarify the reaction of plants to mild salt stress.

In conclusion, these preliminary experiments demonstrated that a mild salt stress $(10 \mathrm{mM} \mathrm{NaCl})$ applied to container-grown Silverhill Satsuma mandarin trees under greenhouse conditions can result in improved fruit quality in terms of juice characteristics, although the fruit size may be reduced. Water stress can have a similar effect in addition to promoting rind color development. Longterm cumulative effect of mild salt stress should be investigated to evaluate the physiological response of citrus trees to drought and salt stress caused by irrigation water containing salt, in particular in Satsuma mandarin trees. Further investigations may enable to demonstrate the optimum water status that will result in both increased fruit juice sugar levels and optimal fruit size.

\section{References}

1) Kramer, P. J. \& Boyer, J. S. (1995): Water relations of plants and soils. Academic Press, San Diego, Calif.

2) Francois, L. E. \& Clark, R. A. (1980): Salinity effects on yield and fruit quality of Valencia orange. J. Am. Soc. Hortic. Sci., 105, 199-201.

3) Hoagland, D. R. \& Arnon, D. I (1950): The water culture method for growing plants without soil. Circular Calif. Agric. Exp. Stn. Univ. Calif., Berkeley, No. 347.

4) Levy, Y., Shalhevet, J. \& Bielorai, H. (1979): Effect of irrigation regime and water salinity on grapefruit quality. J. Am. Soc. Hortic. Sci., 104, 356-359.

5) Lloyd, J., Syvertson, J. P. \& Kriedemann, P. E. (1987): Salinity effects on leaf water relations and gas exchange of Valencia orange, Citrus sinensis (L.) Osbeck, on rootstocks with different salt exclusion characteristics. Aust. J. Plant Physiol., 14, 605-617.

6) Maas, E. V. (1993): Salinity \& citriculture. Tree physiol., 
12, 195-216

7) Meyer, R. F. \& Boyer, J. S. (1981): Osmoregulation, solute distribution, and growth in soybean seedlings having low water potentials. Planta, 151, 482-489.

8) Morgan, J. M. (1984): Osmoregulation and water stress in higher plants. Annu. Rev. Plant Physiol., 35, 299-319.

9) Morinaga, K., Ikeda, F. \& Kihara, T. (1984): Studies on the photosynthesis and fruit production in citrus. 2 . The effects of water stress on photosynthetic rates in satsuma mandarin trees. Bull. Shikoku Natl. Agric. Exp. Stn., 45, 157-166 [In Japanese with English summary].

10) Morinaga, K. \& Ikeda, F. (1991): Photosynthetic characteristics and fruit productivity of satsuma mandarin (Citrus unshiu Marc.) trees under plastic greenhouse culture. J. Jpn. Soc. Hortic. Sci., 60, 61-69 [In Japanese with English summary].

11) Mukai, T. \& Kadoya, K. (1994): Citrus. In Horticulture in Japan. eds. Konishi, K. et al., Asakura Publishing Co. Ltd, Tokyo, Japan, 14-22 [In Japanese].

12) Nieves, M., Garcia, A. \& Cerda, A. (1991): Effect of salinity and rootstock on lemon fruit quality. J. Hortic. Sci., 66, 127-130.

13) Ozubun, J. L., Volk, Rt. J. \& Jackson, W. A. (1975): Effect of potassium deficiency on photosynthesis, respiration and the utilization of photosynthetic reductant by immature bean leaves. Crop Sci., 5, 69-75.

14) Saunt, J. (1990): Citrus varieties of the world: an illustrated guide. Sinclair Int. Ltd, Norwich, England.

15) Spencer, D. \& Possingham, J. V. (1960): The effect of nutrient deficiencies on the Hill reaction of isolated chloroplasts from tomato. Aust. J. Bio. Sci., 13, 441-451.

16) Suzuki, T. et al. (1981): The effect of water stress on sugar, organic acid, amino acid and abscisic acid contents in satsuma mandarin fruits and leaves. Bull. Fac. Agric, Shizuoka Univ., 31, 9-20 [In Japanese with English summary].

17) Sykes, S. R. (1992): The inheritance of salt exclusion in woody perennial fruit species. Plant Soil, 146, 123-129.

18) Walker, R. R. (1986): Sodium exclusion and potassiumsodium selectivity in salt-treated Trifoliate orange (Poncirus trifoliata) and Cleopatra mandarin (Citrus reticulata) plants. Aust. J. Plant Physiol., 13, 293-303.

19) Yamazaki, T. et al. (1990): Studies on root-zone restrictive culture of satsuma mandarin. 1.Effects of root-zone restriction on growth and number of flowers. J. Jpn. Soc. Hortic. Sci., 51 (Suppl. 1), 22-23 [In Japanese].

20) Ziska, L. H., Seemann, J. R. \& DeJong, T. M. (1990): Salinity induced limitations on photosynthesis in Prunus salicina, a deciduous tree species. Plant Physiol., 93, 864-870. 